\title{
Effect of Transient Maternal Hypotension on Apoptotic Cell Death in Foetal Rat Brain
}

\author{
Hamit Özyürek ${ }^{1}$, Sibel Bayrak², Bilge Pehlivanoğlu², Pergin Atilla ${ }^{3}$, Zeynep Dicle Balkanc1², \\ Nur Çakar', Banu Anlar ${ }^{1}$
}

\author{
'Pediatric Neurology Unit, Department of Pediatrics, Hacettepe University Faculty of Medicine, Ankara, Turkey \\ ${ }^{2}$ Department of Physiology, Hacettepe University Faculty of Medicine, Ankara, Turkey \\ ${ }^{3}$ Department of Histology and Embryology, Hacettepe University Faculty of Medicine, Ankara, Turkey
}

Background: Intrauterine perfusion insufficiency induced by transient maternal hypotension has been reported to be associated with foetal brain malformations. However, the effects of maternal hypotension on apoptotic processes in the foetal brain have not been investigated experimentally during the intrauterine period.

Aims: The aim of this study was to investigate the effects of transient maternal hypotension on apoptotic cell death in the intrauterine foetal brain.

Study Design: Animal experimentation.

Methods: Three-month-old female Wistar albino rats were allocated into four groups ( $\mathrm{n}=5$ each). The impact of hypoxic/ischemic injury induced by transient maternal hypotension on the 15 th day of pregnancy (late gestation) in rats was investigated at 48 (H17 group) or 96 hours (H19 group) after the insult. Control groups underwent the same procedure except for induction of hypotension (C17 and H17 groups). Brain sections of one randomly selected foetus from each pregnant rat were histopathologically evaluated for hypoxic/ischemic injury in the metencephalon, diencephalon, and telencephalon by terminal transferase-mediated dUTP nick end labelling and active cysteine-dependent aspartate-directed protease-3 (caspase-3) positivity for cell death.

Results: The number of terminal transferase-mediated dUTP nick end labelling $(+)$ cells in all the areas examined was comparable in both hypotension and control groups. The H17 group had active caspase-3 $(+)$ cells in the metencephalon and telencephalon, sparing diencephalon, whereas the $\mathrm{C} 19$ and $\mathrm{H} 19$ groups had active caspase-3 $(+)$ cells in all three regions. The number of active caspase- $3(+)$ cells in the telencephalon in the H19 group was higher compared with the metencephalon and diencephalon and compared with H17 group $(\mathrm{p}<0.05)$.

Conclusion: Our results suggest that prenatal hypoxic/ischemic injury triggers apoptotic mechanisms. Therefore, blockade of apoptotic pathways, considering the time pattern of the insult, may constitute a potential neuroprotective approach for the detrimental effects of prenatal hypoperfusion. (Balkan Med J 2014;31:88-94).

Key Words: Apoptosis, foetal rat brain, hypotension, hypoxic/ischemic injury, pregnancy
Maternal hypotension during gestation is associated with foetal brain malformations (1-3). The brain stem and midbrain are particularly vulnerable to severe maternal hypotension. Intrauterine hypoxic/ischemic injury as a result of reduced utero-placental blood flow has been linked to serious neurological deficits in the offspring including cranial nerve palsies, abnormal brain stem-evoked responses, and cerebral palsy (4). Furthermore, several case reports demonstrate facial limb hypogenesis syndrome (5), arthrogryposis multiplex (6), and paraplegia (7) associated with maternal hypotension. Therefore, cerebral hypoxic/ischemic injury in the foetus induced by maternal hypotension contributes to neonatal morbidity and mortality (8).

Although these various outcomes have been known for years, the pathophysiology of foetal brain malformations re- lated to maternal perfusion failure is still unclear. Necrosis and apoptosis have been proposed as possible pathways that lead to cerebral pathology in the foetus $(3,9)$. Not only the form and the extent of neuronal death but also the time course of the injury depend on the severity of the ischemic insult (9). Accordingly, we previously observed a significant increase in apoptosis in the hippocampal region, periventricular matrix, and cerebral cortex of newborns on postnatal days 1 and 28, which was dependent on the timing and severity of intrauterine hypotension $(3,10)$. As mentioned above, the effects of maternal hypotension on development of the foetal brain have been reported in a limited number of studies in the postnatal period, but, to our knowledge, not in the antenatal period. Therefore, we aimed to investigate the effects of transient systemic maternal hypotension on apoptotic cell death in the in- 
trauterine foetal brain by exploring cerebral hypoxic/ischemic injury at 48 and 96 hours after the induction of hypotension.

\section{MATERIAL AND METHODS}

\begin{abstract}
Animals
Three-month-old female Wistar albino rats were included in this study. The animals were housed with a fertile male of the same strain and daily vaginal specimens were gathered to determine the first day of pregnancy, as indicated by the presence of sperm in the vaginal smears. Pregnant rats were randomised into four groups $(n=5$ for each) as follows: control 17 days (C17) (sham operation on the $17^{\text {th }}$ day of pregnancy); hypotension 17 days (H17) (hypotension on the $17^{\text {th }}$ day of pregnancy); control 19 days (C19) (sham operation on the $19^{\text {th }}$ day of pregnancy); and hypotension 19 days (H19) (hypotension on the $19^{\text {th }}$ day of pregnancy). Animals were housed under standard conditions at $21 \pm 2^{\circ} \mathrm{C}$ and $30-70 \%$ relative humidity, with a $12 \mathrm{~h}$ dark/12 h light illumination sequence (lights were on between 07.00 and $19.00 \mathrm{~h}$ ) and ad libitum access to water and standard pellet rat chow. All animal experiments were conducted in accordance with the National Institutes of Health (NIH) Guide for the Care and Use of Laboratory Animals and approved by the Hacettepe University Institutional Ethics Committee for the Care and Use of Experimental Animals, Ankara, Turkey.
\end{abstract}

\section{Experimental protocol}

All surgical procedures were initiated from 09.00 to $10.00 \mathrm{~h}$ and carried out under anaesthesia with ketamine $(90 \mathrm{mg} / \mathrm{kg}$, intramuscular [i.m.], Richter Pharma GesmbH \& CoKG, Wels, Austria) and xylazine $(10 \mathrm{mg} / \mathrm{kg}$, [i.m.]; Bayer AG. Leverkusen, Germany). Pregnant rats underwent surgery on the $15^{\text {th }}$ day of pregnancy $(3,10)$. Body temperature was monitored with a rectal probe (BIOPAC SS6L, BIOPAC Systems Inc., California, USA) and maintained at $37^{\circ} \mathrm{C}$ by a heating lamp throughout the experiment. Heart rates were recorded by using ECG needle electrodes placed on the right and left forelimbs and left hindlimb. The right femoral artery was dissected free of the associated vein and nerve and a catheter filled with heparinised saline $(100 \mathrm{U} / \mathrm{mL})$ was inserted. The catheterised femoral artery was joined to a pressure transducer (BIOPAC SS13L, BIOPAC Systems Inc., California, USA), which was connected to a data acquisition/analysis system (BIOPAC MP30, BIOPAC Systems Inc., California, USA) to monitor blood pressure. After a 30-minute stabilisation period following catheterisation, systemic hypotension was induced by blood withdrawal (approximately $1 \mathrm{~mL}$ per $100 \mathrm{~g}$ body weight) within 5 minutes in hypotension groups, as described previously $(10,11)$. As clamping of the uterine vasculature for 30 minutes was previously reported to be sufficient to cause damage in the foetal brain (12), mean arterial blood pressure (MABP) was maintained at $50 \mathrm{mmHg}$ for a period of 30 minutes. Thereafter, the withdrawn blood was slowly re-infused over 10 minutes and the surgical procedure was terminated. Control groups underwent the same procedure except for blood withdrawal and induction of hypotension. Rats were allowed to recover for either 48 hours (C17 and H17 groups) or 96 hours (C19 and H19 groups). On the day of sacrifice (i.e., on the $17^{\text {th }}$ or $19^{\text {th }}$ day of pregnancy), all the animals were anaesthetised as described above, abdomens were opened with a low midline incision, and one foetus was selected randomly from each pregnant rat and included in the H17, C17, H19, and C19 groups ( $\mathrm{n}=5$ for each). Foetuses were immediately decapitated; the brains were isolated and fixed for 48 hours in $10 \%$ buffered formaldehyde (Merck, Darmstadt, Germany), and embedded in paraffin according to standard procedures for histological examination. Mothers were sacrificed with anaesthesia overdose and exsanguination.

\section{Histopathology and immunohistochemistry}

Histopathological evaluation of brain sections was performed in the whole area from each coronal section at x100 and x400 magnification by two examiners blinded to the groups. Three major embryological brain areas, the metencephalon, diencephalon, and telencephalon, were examined in all sections. After fixation in 10\% buffered formaldehyde, brain samples were processed according to the routine tissue processing technique and embedded in paraffin. For each animal, 10 serial 5 -cm sections were stained with haematoxylineosin (H\&E). The presence of tissue destruction, necrosis, and haemorrhage in the metencephalon, diencephalon, and telencephalon was investigated.

Apoptosis was detected by the terminal transferase-mediated dUTP nick end labelling (TUNEL) method (ApopTag Kit, Appligene Oncor, France) and caspase-3 activation, as described previously $(13,14)$. In brief, slides were deparaffinised, hydrated in decreasing concentrations of ethanol, and incubated with $20 \mu \mathrm{g} / \mathrm{mL}$ proteinase $\mathrm{K}$ at room temperature for 15 minutes. Endogenous peroxidase was blocked in $3.5 \%$ hydrogen peroxide at room temperature for 10 minutes. After washing, nick-end labelling was carried out with terminal deoxynucleotidyl transferase (TdT) and digoxigenin-dUTP at $37^{\circ} \mathrm{C}$ for 1 hour. Thereafter, the sections were washed twice, blocked with $1 \%$ non-immune serum at room temperature for 1 hour, and incubated with peroxidase-conjugated anti-digoxigenin antibody $(1: 300)$. Visualisation was done with diaminobenzidine and background staining with methyl green. First, TUNEL $(+)$ cells showing intense nuclear staining, shrinkage, peripheral condensation, and nuclear fragmentation were initially screened and identified at low magnification. Thereafter, all TUNEL $(+)$ cells in the whole areas of the telencephalon, diencephalon, and metencephalon in 10 serial sections from each section were counted at $\times 400$ magnification by two examiners blinded to the groups. The mean of two examiners' counts was used for evaluation.

Activated caspase- 3 immunoreactivity was detected by an immunostaining procedure on brain sections. In brief, slides were deparaffinised, hydrated in decreasing concentrations of ethanol, incubated with $10 \mathrm{mM}$ sodium citrate buffer (pH: 6.0) for 30 minutes for antigen retrieval, rinsed, and incubated with $3.5 \%$ hydrogen peroxide at room temperature for 10 minutes. After washing, slides were incubated with $1 \%$ non-immune serum at room temperature for 10 minutes. Non-immune serum was removed and incubation with polyclonal rabbit anti-cleaved caspase-3 antibody (1:100; Oncogene, San Diego, USA) was performed overnight at $4^{\circ} \mathrm{C}$. The next day, slides were washed and incubated with biotinylated secondary antibody (biotin-labelled goat anti-rabbit in phosphate-buffered saline, Zymed Histostain kit) at room temperature for 30 minutes. Following this step, sections were washed and incubated with streptavidin-peroxidase conjugate (streptavidin-conjugated horseradish peroxidase 
in phosphate-buffered saline, Zymed Histostain kit) for 30 minutes. After a final wash in phosphate-buffered saline, the peroxidase activity was visualised by incubating the specimens in diaminobenzidine. Haematoxylin was used for counterstaining. Negative control staining was performed by omitting the primary antibody step. Active caspase-3 $(+)$ cells in the whole area from each section were counted at $\mathrm{x} 400$ magnification by two examiners blinded to the groups. The localisation of the cells was recorded as metencephalon, diencephalon, or telencephalon and the mean of two examiners' counts was used for evaluation.

\section{Statistical analysis}

MABP data are presented as mean \pm standard deviation (SD). SPSS 17.0 for Windows (SPSS Inc., Chicago, Illinois, USA) software was used for statistical analysis. The number of mothers and foetuses are indicated by $\mathrm{N}$ and $\mathrm{n}$, respectively. Initial animal characteristics were compared by using one-way analysis of variance (ANOVA) followed by Tukey post hoc test. Pre- and post-hypotension MABP and heart rate were compared by using Student's paired t-test. Group comparison of histopathological data was performed by Kruskal-Wallis (for multiple groups) and Mann-Whitney U (for two groups) tests. Bonferroni correction was applied for multiple comparisons. Differences were considered significant at $\mathrm{p}<0.05$ (two-tailed).

\section{RESULTS}

\section{Animal characteristics}

Body weights of the pregnant rats and the number of foetuses were comparable among the groups. Hypotension and control groups had similar initial MABP (Table 1). In the hypotension groups, MABP during the hypotensive period was significantly lower than in the pre-hypotensive period (Table 1), confirming the successful induction of systemic hypotension.

\section{Evaluation of apoptosis in brain sections}

No macroscopic haemorrhage or necrosis was observed in brain tissues. Microscopic evaluation of H\&E-stained sections revealed localised oedematous regions and necrotic cells in the periventricular area 96 hours after the induction of hypotension (H19 group) (Figure 1).

TUNEL $(+)$ cells were detected in metencephalon, diencephalon, and telencephalon in the H17 group, whereas they were observed only in the telencephalon in the control counterparts (C17 group). Both C19 and H19 groups had TUNEL $(+)$ cells in the metencephalon, diencephalon, and telencephalon. The number of TUNEL (+) cells in the metencephalon, diencephalon, and telencephalon was comparable in both hypotension and control groups (Figure 2, Table 2).

Active caspase- $3(+)$ cells were detected in the metencephalon and telencephalon in the H17 group and in the metencephalon in the $\mathrm{C} 17$ group. Interesting enough, apoptotic processes were not observed in the diencephalon at 48 hours after the hypotensive insult. On the other hand, both $\mathrm{C} 19$ and
H19 groups had active caspase-3 (+) cells in all three examined areas, the metencephalon, diencephalon, and telencephalon (Figure 3, Table 3), and differences did not reach statistical significance between the $\mathrm{C} 19$ and $\mathrm{H} 19$ groups. The regional comparison revealed a higher number of active caspase-3 $(+)$ cells in the telencephalon compared with the metencephalon and diencephalon in the H19 group $(\mathrm{p}<0.05)$. The number of active caspase- $3(+)$ cells in the telencephalon in the H19 group was found to be higher compared with that in the same area of the H17 group $(\mathrm{p}<0.05)$. There was no significant difference in the number of active caspase-3 (+) cells in the diencephalon and metencephalon between the $\mathrm{H} 17$ and $\mathrm{H} 19$ groups. The number of active caspase-3 $(+)$ cells in the metencephalon, diencephalon, and telencephalon was also comparable in both control groups (Figure 3, Table 3).

\section{DISCUSSION}

Our findings demonstrated that transient maternal hypotension induced on the $15^{\text {th }}$ day of pregnancy accelerated apoptosis in foetal rat brains, particularly 96 hours after the hypoxic/ ischemic episode. The telencephalon was the most prominently affected region, as evidenced by a significantly higher number

TABLE 1. The mean arterial blood pressure levels for each group (mean \pm standard deviation)

\begin{tabular}{lcccc}
\hline & $\mathrm{C} 17$ & $\mathrm{H} 17$ & $\mathrm{C} 19$ & $\mathrm{H} 19$ \\
\hline Initial MABP (mmHg) & $76.3 \pm 13.6$ & $71.9 \pm 4.4$ & $73.1 \pm 8.3$ & $68.5 \pm 7.2$ \\
MABP during hypotension & & $47.9 \pm 3.2^{*}$ & & $49.5 \pm 4.4^{*}$ \\
(mmHg) & & & & \\
\hline
\end{tabular}

C17: control 17 days; H17: hypotension 17 days; C19: control 19 days; H19: hypotension 19 days. $n=5$ pregnant animals per group.

MABP: Mean Arterial Blood Pressure, *indicates significant difference versus corresponding initial MABP

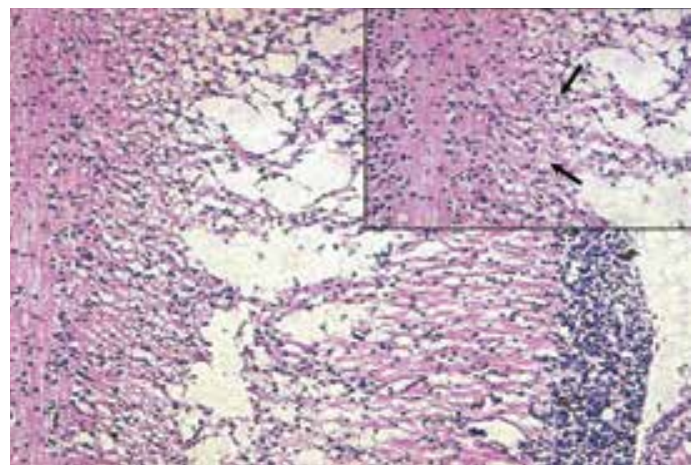

FIG. 1. Histopathological evaluation of foetal brain sections. In the Hypotension 19 days group, localised oedematous changes are observed in the deep lateral periventricular wall in the telencephalon (haematoxylineosin, X100). At higher magnification (haematoxylin-eosin x400), necrotic cells are visible (black arrows) next to oedematous areas 


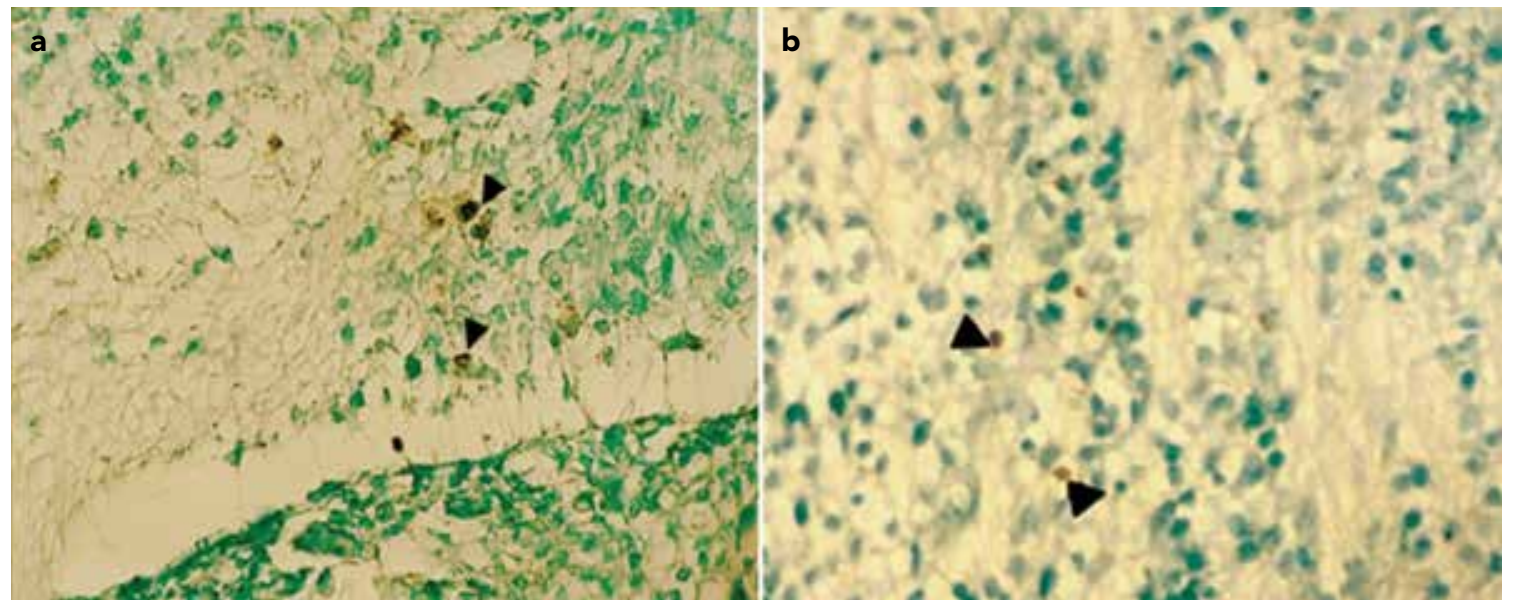

FIG. 2. a, b. Assessment of TUNEL (+) cells in foetal brain sections in Hypotension 17 days (a) and Hypotension 19 days (b) groups. A group of TUNEL $(+)$ cells (black arrows) in the diencephalon region are seen (X400, methyl green counterstain)


FIG. 3. a-d. Assessment of active caspase-3 (+) cells in foetal brain sections in the Control 17 days (a), Hypotension 17 days (b), Control 19 days (c), and Hypotension 19 days (d) groups. Active caspase-3 (+) cells in the metencephalon in the 17 days groups and in the diencephalon in the 19 days groups. (X400, inset: X1000, haematoxylin counterstain)

of active caspase-3 (+) cells. To the best of our knowledge, this is the very first study demonstrating increased apoptosis in intrauterine foetal rat brains after maternal hypotension.

Irreversible cellular injury is defined either by necrosis or apoptosis (15). Apoptosis is an active energy-requiring process (16) distinguished from passive necrotic changes resulting from acute and severe injury to tissues (17) by the presence of cell shrinkage, nuclear pyknosis, chromatin condensation, and genomic fragmentation, which can occur in the absence of an inflammatory response (18). The differences between apoptosis and necrosis, besides energy dependence, are the requirement of time, and new gene transcription and 
TABLE 2. The number of TUNEL (+) cells in rat brain regions

\begin{tabular}{lcccc}
\hline Group & Foetus no. Metencephalon & Diencephalon & Telencephalon \\
\hline Control 17 days & 1 & 0 & 0 & 1 \\
& 2 & 0 & 0 & 4 \\
& 3 & 0 & 0 & 6 \\
Hypotension 17 days & 4 & 0 & 0 & 0 \\
& 5 & 0 & 0 & 0 \\
& 2 & 0 & 14 & 21 \\
Control 19 days & 3 & 2 & 0 & 1 \\
& 4 & 0 & 13 & 0 \\
& 5 & 0 & 0 & 29 \\
& 1 & 10 & 7 & 0 \\
Hypotension 19 days & 2 & 0 & 0 & 0 \\
& 3 & 0 & 37 & 0 \\
& 4 & 2 & 0 & 0 \\
& 2 & 1 & 0 & 0 \\
& 3 & 26 & 1 & 13 \\
& 4 & 0 & 10 & 0 \\
& 5 & 4 & 0 & 0 \\
& 5 & 0 & 0 & 0 \\
\hline
\end{tabular}

The number of TUNEL $(+)$ cells in the metencephalon, diencephalon, and telencephalon is presented ( $\mathrm{n}=5$ foetuses per group)

translation in apoptosis (19). However, in most cases a clearcut distinction between apoptosis and necrosis is not always possible, because both can be observed following hypoxic/ ischemic injury and may even proceed in parallel (20). A number of factors have been suggested to determine whether damaged cells will undergo apoptosis or necrosis, including the cell type, state of maturation, availability of ATP, and the degree of injury (19). Therefore, the pathogenesis of hypoxic/ischemic brain injury is complex. One of the main determinants of injury is most likely the age at the time of the insult (21). It has been postulated that hypoxic/ischemic injury damages selected regions of the immature brain, particularly during the prenatal and neonatal stages (22). In neonatal rats, focal (23) or global cerebral ischaemia (24) can trigger cell death by apoptotic processes. Thus, in immature brains apoptosis has been suggested as the main cellular response to hypoxic/ischemic injury, whereas in adult brains, the ratio of apoptotic to necrotic cells is in favour of the latter $(9,25,26)$. For example, 46 hours after the induction of focal cerebral ischaemia in adult rats, the ratio of apoptotic to necrotic cells was found to be $1 / 9,1 / 6$, and $1 / 13$ in the ischemic core, and inner and outer boundary zones, respectively (15). In line with the above reports, we also observed acceleration of apoptosis in immature foetal brains, particularly 96 hours after experiencing transient hypoxia/ischaemia due to systemic maternal hypotension. Since the cell cycle machinery is intimately linked to apoptosis in developing brains, particular sensitivity
TABLE 3. The number of active caspase- $3(+)$ cells in rat brain regions

\begin{tabular}{lcccc}
\hline Group & Foetus no. & Metencephalon & Diencephalon & Telencephalon \\
\hline Control 17 days & 1 & 21 & 0 & 0 \\
& 2 & 0 & 0 & 0 \\
& 3 & 0 & 0 & 0 \\
Hypotension 17 days & 4 & 0 & 0 & 0 \\
& 5 & 0 & 0 & 0 \\
& 1 & 0 & 0 & 0 \\
Control 19 days & 2 & 39 & 0 & 20 \\
& 3 & 0 & 0 & 0 \\
& 4 & 4 & 0 & 14 \\
& 5 & 0 & 0 & 0 \\
Hypotension 19 days & 1 & 13 & 13 & 0 \\
& 2 & 0 & 50 & 258 \\
& 3 & 16 & 13 & 52 \\
& 4 & 0 & 0 & 0 \\
& 2 & 0 & 0 & 0 \\
& 3 & 0 & 0 & 43 \\
& 4 & 20 & 0 & 221 \\
& 5 & 0 & 12 & 29 \\
& 5 & 0 & 43 \\
\hline
\end{tabular}

The number of active caspase- $3(+)$ cells in the metencephalon, diencephalon, and telencephalon is presented ( $\mathrm{n}=5$ foetuses per group). $\mathrm{p}<0.05$ telencephalon vs. metencephalon or diencephalon in the Hypotension 19 days group, ${ }^{\dagger}<<0.05$ telencephalon in the Hypotension 19 days group vs. telencephalon in the Hypotension 17 days group

of dividing cells to apoptotic stimuli $(27,28)$ may offer an explanation for acceleration of apoptosis (rather than necrosis) in immature foetal brains.

An inflammatory response is induced by hypoxic/ischemic injury, in addition to excitotoxic and oxidative responses in both immature and adult brains. Inflammation has been suggested to be one of the key components of cellular response to hypoxic/ischemic injury in neonatal brains with regard to affected regions and vulnerable cell types (21). However, the immune system is not mature yet and developmental neuronal apoptosis is more active in the foetus compared with newborn. Therefore, the pattern of vulnerability to hypoxic/ischemic injury is expected to differ in foetal brains.

The duration and severity of hypotension may also contribute to the distribution of brain injury, as demonstrated by us and others $(3,10,29,30)$. Clamping of the umbilical cord for 10 minutes caused an injury predominantly in the telencephalon region (29); shorter but repeated episodes (5 minutes, four times) of umbilical cord occlusion damaged the striatum (30). In line with the above findings, in this study, induction of maternal hypotension for 30 minutes damaged mainly the foetal telencephalon. This period was chosen because clamping of the uterine vasculature for 30 minutes was shown to be sufficient to reduce learning ability in rat foetuses, which was associated with a reduction in nitric oxide synthase (NOS) mRNA and activity, confirming the brain damage functionally and molecularly (12). Collectively, these data imply that the 
telencephalon may be the most prominently affected region after transient intrauterine hypoxic/ischemic injury. Because disruption of the telencephalon during the third trimester has been reported to cause multiple neurological impairments (31), accelerated apoptosis in the telencephalon may provide evidence that maternal hypotension during late pregnancy can be associated with future neurological morbidity such as cerebral palsy, cognitive delay, epilepsy, and behavioural problems.

As mentioned earlier, the timing of foetal perfusion failure is also important for perinatal cerebral injury. In human pregnancy, the last trimester has been reported to be the most critical period for the cerebral effects of foetal perfusion failure $(3,32)$. To model this physiological phenomenon that occurs during the natural course of pregnancy, maternal hypotension was induced on the $15^{\text {th }}$ day of pregnancy in rats and we sacrificed animals on the $17^{\text {th }}$ day and $19^{\text {th }}$ day (late term) of the pregnancy, representing the last trimester of human pregnancy. In our previous study in which a similar hypotension protocol was used, we demonstrated increased apoptosis in newborn rat brains on postnatal days 1 and 28 (10). Furthermore, increased apoptosis on postnatal day 28 was positively correlated with the impairment of spatial learning, highlighting the clinical significance of hypoxic/ischemic injury in late pregnancy. In the current study, we showed a progressive increase in apoptosis after hypotension, which was mediated via caspase-dependent pathways. Overall, these data suggest that the timing of foetal perfusion failure is one of the major contributors of cerebral hypoxic/ischemic injury.

In conclusion, the novel finding of this study is the accelerated foetal cerebral apoptosis within the intrauterine period. The potentially detrimental effects of increased apoptosis on foetal brain development and postnatal learning warrant further studies.

Ethics Committee Approval: Ethics committee approval was received for this study from Hacettepe University Institutional Ethics Committee for the Care and Use of Experimental Animals.

\section{Informed Consent: N/A}

Peer-review: Externally peer-reviewed.

Author contributions: Concept - H.Ö., B.A., B.P., S.B.; Design - H.Ö., S.B., B.P., B.A., N.Ç.; Supervision - B.A., Z.D.B., N.Ç.; Resource - S.B., B.P., Z.D.B., P.A., N.Ç.; Materials - S.B., B.P., H.Ö., P.A., Z.D.B., N.Ç., B.A.; Data Collection\&/or Processing - S.B., B.P., H.Ö., P.A.; Analysis\&/or Interpretation - S.B., H.Ö., B.P.; Literature Search - H.Ö., S.B., B.P., B.A.; Writing - S.B., B.P., H.Ö.; Critical Reviews - H.Ö., S.B., B.P., B.A., Z.D.B., P.A., N.Ç.

Conflict of Interest: No conflict of interest was declared by the authors.

Financial Disclosure: This study was supported by research grants from The Research Foundation of Hacettepe University (project codes: 02.01.101.018 and 01 G 019).

\section{REFERENCES}

1. Ornoy A, Benady S, Kohen-Raz R, Russell A. Association between maternal bleeding during gestation and congenital anomalies in the offspring. Am J Obstet Gynecol 1976;124:474-8.

2. Sanner G. Pathogenetic and preventive aspects of non-progressive ataxic syndromes. Dev Med Child Neurol 1979;21:663-71. [CrossRef]

3. Apak RA, Anlar B, Atilla P, Cakar N. Transient intrauterine hypotension: effect on newborn rat brain. Pediatr Res 2001;49:45-9. [CrossRef]

4. Lipson AH, Gillerot Y, Tannenberg AE, Giurgea S. Two cases of maternal antenatal splenic rupture and hypotension associated with Moebius syndrome and cerebral palsy in offspring. Further evidence for a utero placental vascular aetiology for the Moebius syndrome and some cases of cerebral palsy. Eur J Pediatr 1996;155:800-4. [CrossRef]

5. Lipson AH, Webster WS, Brown-Woodman PD, Osborn RA. Moebius syndrome:animal model--human correlations and evidence for a brainstem vascular etiology. Teratology 1989;40:339-50. [CrossRef]

6. Farrell K, McGillivray BC. Arthrogryposis following maternal hypotension. Dev Med Child Neurol 1983;25:648-50. [CrossRef]

7. Weyerts LK, Jones MC, James HE. Paraplegia and congenital contractures as a consequence of intrauterine trauma. Am J Med Genet 1992;43:751-2. [CrossRef]

8. Vexler ZS, Ferriero DM. Molecular and biochemical mechanisms of perinatal brain injury. Semin Neonatol 2001;6:99-108. [CrossRef]

9. Nakajima W, Ishida A, Lange MS, Gabrielson KL, Wilson MA, Martin $\mathrm{LJ}$, et al. Apoptosis has a prolonged role in the neurodegeneration after hypoxic ischemia in the newborn rat. $J$ Neurosci 2000;20:7994-8004.

10. Tombakoglu M, Durakoglugil M, Kale G, Orer HS, Bulun A, Anlar B. Transient intrauterine hypotension causes apoptosis in fetal rat brain and affects learning. Pediatr Res 2003;53:977-82. [CrossRef]

11. Bayrak S, Pehlivanoglu B, Balkanci ZD, Ozyurek H, Aksoy Y, Atilla P, et al. The effects of transient systemic hypotension on renal oxidative status, morphology and plasma nitric oxide levels in pregnant rats. $J$ Matern Fetal Neonatal Med 2009;22:528-36. [CrossRef]

12. Cai Z, Xiao F, Lee B, Paul IA, Rhodes PG. Prenatal hypoxia-ischemia alters expression and activity of nitric oxide synthase in the young rat brain and causes learning deficits. Brain Res Bull 1999;49:359-65. [CrossRef]

13. Gavrieli Y, Sherman Y, Ben-Sasson SA. Identification of programmed cell death in situ via specific labeling of nuclear DNA fragmentation. $J$ Cell Biol 1992;119:493-501. [CrossRef]

14. Koizumi H, Ohkawa I, Tsukahara T, Momoi T, Nakada K, Uchikoshi T. Apoptosis in favourable neuroblastomas is not dependent on Fas (CD95/APO-1) expression but on activated caspase 3 (CPP32). J Pathol 1999;189:410-5. [CrossRef]

15. Li Y, Powers C, Jiang N, Chopp M. Intact, injured, necrotic and apoptotic cells after focal cerebral ischemia in the rat. J Neurol Sci 1998;156:11932. [CrossRef]

16. Stefanis L. Caspase-dependent and -independent neuronal death:two distinct pathways to neuronal injury. Neuroscientist 2005;11:50-62. [CrossRef]

17. Edinger AL, Thompson CB. Death by design: apoptosis, necrosis and autophagy. Curr Opin Cell Biol 2004;16:663-9. [CrossRef]

18. Edwards AD, Mehmet H. Apoptosis in perinatal hypoxic-ischemic cerebral damage. Neuropathol Appl Neurobiol 1996;22:494-8. [CrossRef]

19. Taylor DL, Edwards AD, Mehmet H. Oxidative metabolism, apoptosis and perinatal brain injury. Brain Pathol 1999;9:93-117. [CrossRef]

20. Northington FJ, Ferriero DM, Graham EM, Traystman RJ, Martin LJ. Early neurodegeneration after hypoxia-ischemia in neonatal rat is necrosis while delayed neuronal death is apoptosis. Neurobiol Dis 2001;8:207-19. [CrossRef]

21. Vexler ZS, Yenari MA. Does inflammation after stroke affect the developing brain differently than adult brain? Dev Neurosci 2009;31:378-93. [CrossRef] 
22. Hossain MA. Hypoxic-ischemic injury in neonatal brain:involvement of a novel neuronal molecule in neuronal cell death and potential target for neuroprotection. Int J Dev Neurosci 2008;26:93-101. [CrossRef]

23. Hill IE, MacManus JP, Rasquinha I, Tuor UI. DNA fragmentation indicative of apoptosis following unilateral cerebral hypoxia-ischemia in the neonatal rat. Brain Res 1995;676:398-403. [CrossRef]

24. Beilharz EJ, Williams CE, Dragunow M, Sirimanne ES, Gluckman PD. Mechanisms of delayed cell death following hypoxic-ischemic injury in the immature rat:evidence for apoptosis during selective neuronal loss. Brain Res Mol Brain Res 1995;29:1-14. [CrossRef]

25. Edwards AD, Yue X, Cox P, Hope PL, Azzopardi DV, Squier MV, et al. Apoptosis in the brains of infants suffering intrauterine cerebral injury. Pediatr Res 1997;42:684-9. [CrossRef]

26. Johnston MV. Excitotoxicity in neonatal hypoxia. Ment Retard Dev Disabil Res Rev 2001;7:229-34. [CrossRef]

27. Sidhu RS, Tuor UI, Del Bigio MR. Nuclear condensation and fragmentation following cerebral hypoxia-ischemia occurs more frequently in immature than older rats. Neurosci Lett 1997;223:129-32. [CrossRef]
28. Yue X, Mehmet H, Penrice J, Cooper C, Cady E, Wyatt JS, et al. Apoptosis and necrosis in the newborn piglet brain following transient cerebral hypoxia-ischaemia. Neuropathol Appl Neurobiol 1997;23:16-25. [CrossRef]

29. Mallard EC, Gunn AJ, Williams CE, Johnston BM, Gluckman PD. Transient umbilical cord occlusion causes hippocampal damage in the fetal sheep. Am J Obstet Gynecol 1992;167:1423-30. [CrossRef]

30. Mallard EC, Williams CE, Johnston BM, Gunning MI, Davis S, Gluckman PD. Repeated episodes of umbilical cord occlusion in fetal sheep lead to preferential damage to the striatum and sensitize the heart to further insults. Pediatr Res 1995;37:707-13. [CrossRef]

31. Robinson S. Systemic prenatal insults disrupt telencephalon development: implications for potential interventions. Epilepsy Behav 2005;7:345-63. [CrossRef]

32. Back SA, Luo NL, Borenstein NS, Levine JM, Volpe JJ, Kinney HC. Late oligodendrocyte progenitors coincide with the developmental window of vulnerability for human perinatal white matter injury. $J$ Neurosci 2001;21:1302-12. 